\title{
Some Methodological and Theoretical Questions of Infosphere Development
}

\author{
Maxim Polyakov ${ }^{1}$, Igor Khanin ${ }^{2}$, Nikolay Bormatenko ${ }^{3}$ \\ ${ }^{1}$ NoosphereVentures Inc., USA \\ ${ }^{2}$ The National University of Water Management and Nature Resources Use, Ukraine \\ ${ }^{3}$ MS-Ukraine Noosphere Ventures Inc.
}

\begin{abstract}
Information technologies" today is an application of physical technologies to the information practices. Technologies of information have not started yet. To understand the infosphere development, we offer the model of Paradigmatic Innovation Development developed on the base of quasi-physical approach to non-physical phenomena.
\end{abstract}

\section{Introduction}

It is appropriately to apply term "technology" to objective, scientifically substantiated approaches to producing. Then, information technologies (IT) which evoked revolutionary changes in the sphere of informational phenomena (infosphere) including society, economy and business, in reality, come to the application of physical (not informational) technologies of data processing to the informational practices (not technologies).

Of course, all terms are more or less conventional. But their conventionality should be explicit. We don't have that in the case of IT. It gives opportunities to use imperfect technologies and digitized practices stating that IT has reached the peak of its development [1]. In reality IT, probably, didn't even start. This contradiction coupled with unsolved practical problems of infosphere requires the strengthening of its methodological and theoretical base.

\section{Model of Paradigm Innovation Development}

To understand where the infospere development is now and where it is going, let us use the model of Paradigm Innovation Development (PIDev). It is developed on the base of quasi-physical approach to non-physical phenomena the idea of which was suggested by Merab Mamardashvili [2]. Main features of the model are represented in Figure 1. In Figure 1, x-axis represents the time of development, $y$-axis represents the scientific level of innovations, and $\mathrm{z}$-axis represents the sphere of innovation development. Quasi-physical approach to nonphysical phenomena, at this case, lies in reduction of physical and non-physical (informational) spheres of innovations to the common scheme of development.

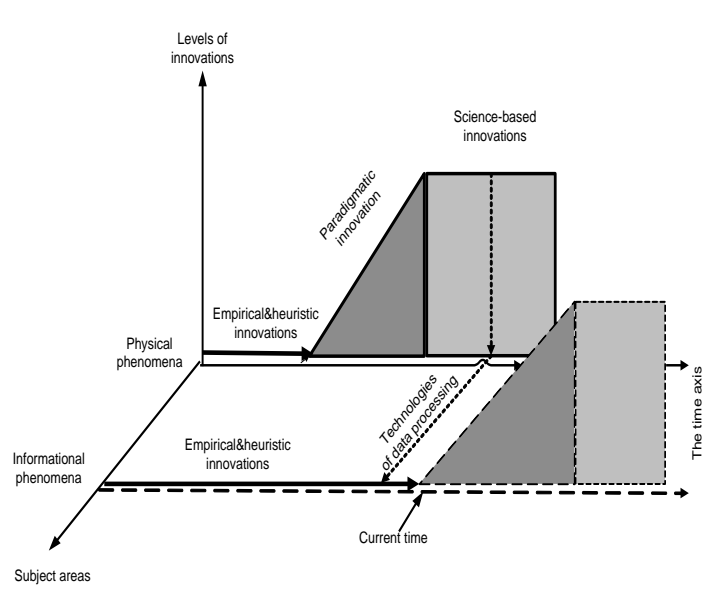

Figure 1. The phases of innovation development [3]

According to Figure 1, innovations in any sphere start from guesswork, associations and analogies, not borne out by scientific knowledge. This first phase is called by us empirically-heuristical phase (EHP). When the sufficient experience is gained, the possibility and necessity to multiply and speed up the innovations appear in the way of building and usage of scientific theories.

Transition to the phase of scientifically substantiated innovations is going through the phase of trial theories - paradigms. This word gives the name to the model.

Following the Figure, the information technologies, in fact, are technologies of data processing, which have appeared in the sphere of physical phenomena belonging to the phase of scientifically substantiated innovations, and found their application in another sphere. This is the sphere of information phenomena which is in the empirically-heuristical phase of its development.

Empirically-heuristical phase is characterized by the deficit of scientific knowledge standing behind the essence of information phenomena, adaptation of a human to information technologies and depletion of explicit opportunities of adaptation of technologies to 
a human, usage of guesses (heuristics) and analogies (empiricism), devotion to non-direct methods of cognition (mathematical, statistical and other modeling); interdisciplinary approach which transforms into eclectic mix of different forms of cognition (practical, scientific, philosophical, spiritual), and usage of the concepts similar to golems, homunculus, eternal engines, and artificial intellect as a radical remedy for problems.

EHP is necessary for the accumulation of empirical material and ideas which allow understanding and controlling the ontology of programs, data, and organizations. Under the quasi-physical approach, the ontology answers the question how these objects are built and built-in into the world. EHP will end up for the infospere when real information technologies replace empirically-heuristical approaches of the application of data processing physical technologies to "digitize" existing information practices.

At the current moment, there is more than enough of empirical material for transition of the infosphere to paradigmatic phase of development, and to the next phase of highly productive scientifically substantiated innovations. The specifics of paradigmatic phase are widening and deepening of the ontological picture of reality in the way of inclusion of signs as the condition of adaptation of technologies to a human and society (in contrast to the adaptation of a human to technologies), accent on the ontology (essence) of information (more precisely, sign) objects as a key factor of the infosphere development, usage of positive and negative experience, collected in the empirically-heuristical phase as an experimental base and ideas source, formation and application of the methodology of Vertical Integration of Knowledge (VIK) which methods are different from the methods usual for empirically-heuristical and scientifically substantiated phases.

Model PIDev can be viewed as a result of the application of cyclical approach of Nikolay Kondratyev, Joseph Schumpeter and neoschumpeterians (Chris Freeman, Carlota Perez) to longer time periods than Kondratyev's ones. It appeared as a participants' reflection of the real innovation process which consisted in the development of the forms and structures of humanmachine data.

\section{Some specifics of terminology}

Bellow you will find a conceptual scheme (model), reflecting our ideas of the way, how the work should be done in the paradigm phase. We should take into account that there are significant differences between the phases, despite their commonality. Each phase forms its own innovative systems, including relations of practice with an academic science, whether it is natural or humanitarian. In such environment the same terms change their meaning up to homonymy.
Boundaries between phases are usually unclear; therefore it is hardly reasonable for each phase to have own terminology. We should just keep in mind that the terms, while transferring from phase to phase, change their meaning. This is normal. Their meaning should be derived from context or specifically stipulated.

During phase transitions the problem is aggravated and such cases need to be discussed. Let us consider the word "system". It is obvious that these words mean a large and complex physical body, consisting of the other physical bodies. It is critical that transformation of a multitude of physical bodies into a system does not change their ontology. It is clear that in this case the term "system" has quite abstract logical-mathematical nature and by the meaning it is close to the term "structure".

A diametrically opposite example is an information system. It consists of heterogeneous elements (computers, data, programs, people, organizations, etc.). What is the result of combining these articles? Is it a complex body of physical, biological, economic, social or other nature? The epithet "informational" does not answer this question, because the concept of information is still controversial. This question can be answered using the principle of emergency. According to this principle, combining heterogeneous elements results in formation of a unique nature that is called a system. Thus, in this case the term "system" is applied to the objects, which, due to their uniqueness, have principally non-determinable nature.

Thereby it is not only information systems, but also programs, databases and organizations, consisting of heterogeneous elements, which also have no their own ontology. These objects are peculiar to empiric-heuristic phase of development and we really need to give them some names. Therefore, the term "system", derived from natural sciences, being in the scientific phase of development, has fundamentally changed its meaning. Thus, the collocation "information system" is equal to impossibility of the scientific study of an object, producing the phenomena under study, by the way of identifying its essence (ontology). It looks paradoxical, but such state of things is natural for empirical-heuristic phase.

The paradox can be solved through implementation of the suggested approach. For this purpose we need software, informational and organizational systems to become the impersonation of the concept "sign construction".

A similar metamorphosis occurred with the world "model". In the field of natural sciences the model is a simplified physical or symbolic analogy of a wellknown and similarly understood object. However, in the area of information phenomena it is more or less formalized hypothetical description of a unique and, therefore, poorly understood object. 
By the word "information" they designate messages, consisting of signs, as well as one of measures of message impact on recipients. For instance, Russell Ackoff and Fred Emery distinguish three such measures: motivation, information and instruction [4]. In our opinion it is enough. In order to designate information in terms of messages and data, we suggest using the terminology based on the root "sign".

We will consider "technology" as scientifically grounded and, therefore, objective ways of actions. For designation of the formalized ways, although based on assumptions and analogies, we will use the world "practices". Having got scientific explanation and being improved on this basis, the practices turn into technologies. Technologies as well as information are present in the information technologies in the designated sense. However, technologies are represented by data, and physical processes of data handling and information exist in the form of information practices, which still have no scientific rationale and status of technologies.

We should also draw your attention to the term "user". The information technologies (actually physical technologies of data processing) are one of the parts of informational and economic sphere, and not vice-versa. Accordingly, economists and managers are those who are and who have to be responsible for the architecture and state of the whole economic object as sign construction. Therefore it would be a mistake to see them only as clients of information technologies as one of service industries.

\section{The experience of paradigm development of the infosphere}

A purpose of the analysis is to learn from positive and negative experience of paradigm innovations in the infosphere, simultaneously verifying the potential of the suggested models and the tools for explaining what is going on.

Among multiple attempts to implement paradigm innovations, let us consider the following ones: object-oriented analysis and design (OOAD), theory and practice of business processes (TPBP), architecture of enterprises and systems (AES), ontology in information technologies, semantic technologies.

\subsection{Object-Oriented Analysis and Design of computer programs (OOAD)}

OOAD is associated with the name of Grady Booch, an author of a popular book of the same name [5]. The actual purpose of this school was a unification of programs, simplicity of their coding and making amendments because of linking to diverse subject areas or with the course of time. OOAD became one of the first major and partially successful attempts to integrate infosphere and econosphere on the computer basis. De facto, OOAD can also be considered as not well acknowledged attempt to apply the ontological approach, which is similar to ours as it is mentioned in our paper [6].

Programs and data can be considered as the results of spontaneous formalization of separate fragments of organizations. Combining the fragments to form a mosaic, over the time we can have an organization as a whole. Obviously, Peter Brödner, who noted commonality of software and organization support in his paper "Software is Orgware", has the similar views [7].

An undoubted merit of OOAD consists in the fact that it has enhanced the mathematical understanding of the program as an algorithm, having viewed it as an object along with the objects, i.e. things of the subject area. Moreover, OOAD declared the programs to be one of data types. Thereby it actually acknowledged that programs and data are of the same nature, and the difference between them is purely functional. Although, OOAD overlooked the fact that this is a sign nature and they made no proper conclusions, proceeding from this fact.

Acting by intuition, OOAD achieved a few practical goals. We mean the case, when the subject areas are represented by screen devices, actually being the forms of data (windows, menu, action buttons, etc.). In this elementary case, their shapes are permanent and easily described with data of permanent structure. When the economy acts as a subject area, it turns out to be more difficult to find consistency between this subject area and data.

OOAD has not taken into account the fact that there are no direct linkage between program and subject areas. There is data between them. Since in the 1970s Fred Brooks stated that the program has nothing but data processing. Therefore, in order to unify programs it is sufficient to unify data, i.e. to find invariant forms and structures for them. At the same time, data is capable of playing the role of flexible junction between program (physical technologies of data processing), users and subject area (information practices). Data should serve both as a connector and divider. Although, for this purpose, we need to change view of the signifier (data) as well as of the signified, i.e. subject area, being the economic organization.

It is evident that the authors of OOAD intuitively followed the right path; however, just intuition, guesses and analogies are not enough to address such problems. Here we need a consistent system of ideas - mental construction, which can be exemplified by the suggested schematic diagrams. 


\subsection{Theory and practice of business processes (TPBP)}

Theory and practice of business processes, associated with the name of August-Wilhelm Scheer [8], is one more attempt to establish rational relations between machine processing of data and business. It is based on the concept of business process. The author calls it semi-conceptual. It, in fact, admits diverse interpretations. In particular, the author of the concept compares computer program with a blueprint (copy) of business processes.

According to our paradigm, the program can have nothing but data processing. Program semantics is represented by physical (electronic) processes of data processing. Hence, the program does not have direct relation to the economy, if we consider the latter to be a subject area. In fact, the program performs the data processing. Non-informational economic processes are not included into this process. However, according to TPBP, business processes of economic management can be initially described in natural language and further in the language of modeling like UML, wherefrom they should be automatically transformed into program text. It is possible, just provided that the term "business processes" de facto designates the processes of data processing.

In case of using such approach, the key role of data as interlink between business, management and information technologies, simultaneously performing the function of flexible junction, is lost. By default, instead of developing the forms and structures of data, reflecting the area of user's interests by machine data carriers, there is an adaptation of the existing forms and processes of data processing to computer environment. Such an approach does not allow us to enhance the level of integration of business and information technology.

Proceeding from the models, suggested by us, we can make a conclusion that there is an attempt, using exceptionally heuristic and empiric approaches, to carry out paradigm in depth innovation without the appropriate conceptual apparatus. TPBP, probably, tried to separate the economic processes from the data processing ones and this is really needed. Generally, these are different processes with operands and operators of diverse nature. The economic processes, besides the cases of information business, are not transformed into data processing processes. They have more complex interrelations.

\subsection{Architecture of enterprises and systems (AES)}

AES is associated with the name of John Zachman [9]. It is aimed at overcoming disintegration of information technology and business. It is difficult to disagree with the fact of disintegration, although its reason is not explicitly identified.
In our opinion, the reason is a gap between data forms and something that these data signify. With the emergence of computers, different people became responsible for the signifier and the signified. The organizational gap is exacerbated by the existence of parallel systems of data: out-of-machine (user's) and machine (for processing). User's system of data is based on the forms, designed for paper carriers, the other one is based on the same forms, modified in the form of databases on machine carriers. Such state of things leads to organizational gap, when the signifier (processed data) is in the hands of programmers and the objects, designated by this data, are in the hands of the users. In such circumstances alterations of forms and structures are so difficult that in case of certain and quite small semantic variety of data and certain frequency of changes, inevitably occurring in the subject area, the complexity barrier is formed. The experienced developers prefer not to tackle these challenges or to divide them into fragments and it is not very effective.

An answer to the question how the architecture is organized and embedded in its surroundings, i.e. what ontology it has, is absent. Most often, Architectural Design is characterized indirectly in the stage-bystage process of automation (digitization) of enterprise management. At the same time, it is associated with certain characteristics of economic activity, for instance, with achievement of strategic goals.

It results in a paradoxical situation, when the architecture is identified with the existing processes of management digitization, which problems should be addressed by this architecture. Ultimately the Architectural Design is reduced to recommendations, addressed to managers and programmers, to strengthen cooperation in the area of creating Architectural Design as a certain tool for overcoming the disintegration of IT and business.

Thus, the Architectural Design quite rightly raises the problem of disintegration of IT and business. However, concerning the solving, it can be a striking example of practical impossibility to achieve this by empiric and heuristic facilities without clear understanding of the progress of economic and cognitive activities. Within the framework of the suggested mental models an answer to the question "what is architecture?" is: it is "economic organization, being represented by sign construction".

\subsection{Ontology in information technologies}

This school is associated with the name of Thomas Gruber [10]. Emergence of philosophic term "ontology" in the area of IT is not by accident. Probably it was caused by understanding of the necessity to plunge the innovative processes in the infosphere into the maximum depth level, i.e. philosophic level, being the fourth level according to 
the schematic diagram in the phase of paradigm innovations. However, similarly to the concepts of program as object, the enterprise architecture and business processes, the concept of ontology has got unexpected interpretation in IT.

Philosopher Gustav Shpet defined physics as a science of ontology, i.e. science of the essence and existence of physical bodies, biology - living organisms, semiotics - signs [11]. It is obvious that programs, data and economic organizations have a direct relation to signs. Therefore, in order to address the challenges of infosphere development, it is expedient to identify the essence and features of existence, i.e. ontology of signs, having used the abundant experimental material of the interrelated programs, data and organizations.

However, IT took a different track. They related the term "ontology" to the results of empiric and heuristic, i.e. based on guesses and ontologies, formalization of data. The initial objects of formalization are represented by weakly formalized data (texts) or by strongly formalized ones (tables, card-indices, logs, etc.). In any case, it is useful to know the ontology of the generalized organizational sign and its varieties as Shpet understands it. Without this, it is impossible to guarantee obtaining of "natural", i.e. consistent with the experience, invariant forms and structures of data, lacking which their unification and standardization is challenging.

An example of the application of ontological approach in IT shows a necessity to understand the place and role of every phase in broader context of the innovative development. It is provided by the respective schematic diagram. Besides, any phase, represented by its subjects of activity, tries to absolutize and perpetuate the approaches, intrinsic of it, ideas, methods and organizational forms of work. For instance, in empiric and heuristic phase the innovations are created from everything that you have close at hand. Nevertheless, even when the sufficient experience of spontaneous formalization has already been accumulated, and the source material in the form of the existing practices has been exhausted, everybody continues acting by customary methods, i.e. like nature - in evolutionary way.

To create something new, modifying the existing forms and structures - is the same like to fly, imitating birds. A human is capable of acting more effectively. For this purpose people strengthen their intellect, creating something, which does not exist in human nature and society. It is "mental constructions" paradigms, theories and methods, forming a constructive consistency.

In our opinion, the ontology as mental philosophic construction is required for understanding of sign and the formation of sign technologies, i.e. for realization of paradigm innovations in the infosphere. Although IT use this term in other way. In particular, they applied it for designation of the results of empiric and heuristic formalization of texts in natural languages. At the same time there is a situation of ambiguity. What is actually formalized - the text (the signifier) or something that this text signifies? This ambiguity continues in the situations with analysis of data and so called Big Data [12], which, irrespectively from the fact how big is this data, is still semantically homogeneous, thereby limiting the potential circle of analytical tasks.

It can be explained by the fact that the empiric and heuristic phase has its own real dominating philosophy. This philosophy is not obligatory formulated in explicit form. It is represented by such approaches as functionalism, giving rise to such methods as general system and mathematical modeling. This philosophy does not insist on defining the ontology as an essence of objects of innovation, albeit it does not prohibit this definition.

We should acknowledge that till a certain moment it is reasonable as far as the ontology can be identified just after accumulation of a sufficient experience as a result of the performed activity. The model of paradigm innovative development shows that such approaches are natural for empiric and heuristic phase. According to the same model, this phase should be the ultimate one. Therefore, although the terms are not disputable due to their conventional nature, we have to be more careful, calling the physical technologies of data processing to be information technologies, the existing processes of data processing - business processes and dictionaries, describing the subject areas - ontologies. This impedes understanding of the existing state of things as transition to the paradigm phase. Although, on the other hand, thereby we made attempts to identify and address problems, to formulate and address which, we need to have the tools of economy of knowledge.

\subsection{Semantic technologies}

The school, known as semantic web or semantic technologies, associated with the name of Tim Berners-Lee [13]. It naturally raises a question of the decisive role of science of signs in the development of infosphere as far as semantics is an integral part of semiotics, which cannot be separated from syntax and pragmatics. However, in fact, semantic technologies constitute one more empiric and heuristic attempt to enhance the level of machine processing of weakly formalized data. In particular, for this purpose they use the term "ontology" in its empiric and heuristic meaning. At the same time, semantic technologies do not delve into the ontology of programs and organizations and do not try to build a fundamental theory of organization and economic signs, and, moreover, do not form the philosophy, required for this purpose. Semantic technologies continue traditions of the ontology in IT, imitating the human treatment of signs, in particular, texts in natural 
languages. People also do not try to create the scientific and philosophical apparatus to understand and further to address the problem.

According to the model of vertical integration of knowledge, semantic technologies are characterized by zero innovative depth. It means that in terms of the models of paradigm innovative development and vertical integration of knowledge, their results are the digitized practices.

In any case, the results of applying such semantic technologies are represented by sign constructions. In this context the world "construction" means a high degree of formalization. However, such construction cannot be substantiated, unified and optimized, being plunged into a broader "mental construction" of technological level. For this purpose we need the constructions at the level of the applied technologies and further - fundamental theories, and ultimately constructions at the level of methodology and philosophy. Eventually, the sign construction "semantic technologies" is an implementation of the experience and intuition of its authors, being not supported by deeper and more consistent mental formations.

It should be noted that we do not criticize information technologies, OOAD, architectural design, TPBP, ontologies in IT and semantic technologies, but just clarify the correlation between their declarations and something, which is actually behind them. In general, these schools function within the framework of the innovative development, possible for empiric and heuristic phase of innovative development. Using this positive experience as well as the negative one, i.e. not only successes, but also failures, they prepare, and we hope they have already prepared a transition to the phase of paradigm innovations.

\section{The methodology of paradigmatic development of infospere}

Paradigmatic phase has a special regime of innovation activity. "Parabola of Knowledge" illustrates the methodology of work at this phase which consists in Vertical Integration of Knowledge (VIK) (see Figure 2). Phase of scientifically substantiated innovations has the similar parabola, but the levels of activity are more isolated, organizationally formed, and function in the asynchronous regime. To a great extent, their task reduces to the support of achieved level of development inside the limits which are set at the previous paradigmatic phase. Staying in the empirically-heuristical phase, the innovations in the infosphere today are not coming outside the limits of social, economic, business, and other information practices. The achievement of the level of construction and technologies is still their future.

Left semiplane on the Figure 2 corresponds to the function of analysis of the infospere development problem. Right semiplane is a function of synthesis of innovation decisions. Upper semiplane is an area of practice, and lower one is the levels of the forms of knowledge (from constructions and technologies to philosophy and methodology). At the bottom point, on the level of philosophy and methodology, the movement along parabola is coming to the right semiplane. Here is a process of decision making of the practical problems founded at the stage of analysis in the left semiplane of parabola of knowledge.

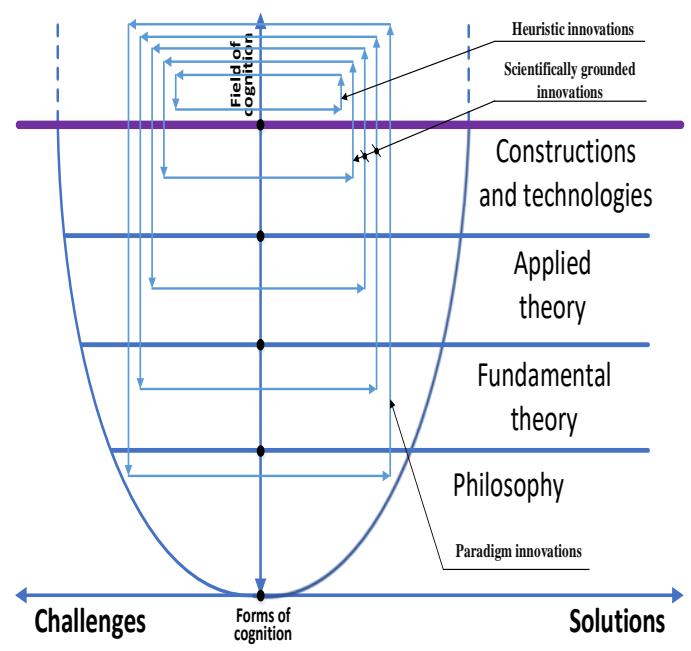

Figure 2. The parabola of knowledge [14]

\section{The analysis of parabola of knowledge in infospere}

At the level of information practices the development of infosphere meets multiple problems. Among them, we can name the slowing down of the velocity of knowledge comparing to potential level, semantic poverty of data, the lack of correspondence between the signifier and signified in the Sign Constructions, and the processing of weakly formalized knowledge.

Trying to solve problems stated above with technological (objective) tools, the researcher meets the lack of the necessary base such as applied theories which could open the ontology of software, data, knowledge, and organizations. Trials to solve that problem without theoretical base, just with help of guesses and analogies (this way is commonly called methodologies), constantly repeat for at least a half of century. In general, they are not very successful. Although, banal but fortunate translation of table forms into computer environment as relation structures of data allowed diffusing the problems.

Failures of the substitution of applied theories with the so-called methodologies force to search fundamental theory which would allow deriving applied theories. It is very natural to connect organizations, software and data with signs and science of signs, semiotics. Organizational semiotics 
of Ronald Stamper [15] and semantic technologies Fensel [16] follow this way. They use the approaches of humanitarian semiotics.

We started the move on this way at the beginning of 80s [17] and came to conclusion that because of empirically-heuristical and half philosophical character of existing semiotics it wasn't appropriate for generation of applied theories which would allow making constructions and technologies.

Analyzing what bothered and still bother development of such science, we come to conclusion that such obstacle is the dominance of the philosophy which associates signs with the special mental world existing parallel to the physical world, modeling but not touching it.

We have found philosophical views necessary for a solution of the problem in the Vladimir Vernadskij's noosphere thinking [18], quasi-physical approach to non-physical phenomena of Merab Mamardashvili [2], and the philosophy of name of Aleksei Losev [19]. Quasi-physical approach is principally different from the physical one by the objects and subjects it focuses on. Quasi-physical objects include physical components, but are not reduced to them.

\section{The synthesis of parabola of knowledge in infospere}

At the level of philosophy and methodology, the formation of parabola of knowledge creates model PIDev and methodology VIK considered by us. At the level of fundamental theory we receive SystemSemiotic Paradigm (SSP) of Sign Construction (SC).

Sign Constructions are formalized sign formations which refer to the sphere of economic organizations. These are software, databases and bases of knowledge, and also social, economic and business organizations by itself. Paradigm is a common core of Sign Constructions, and can be applied to whole their variety. Figure 3 represents SSP.

In Figure 3 the base form of Sign Construction is presented. At its base we see a natural kind of objects which belongs to the area of the interests of user. Natural kind, for example human, differs from the functional class, for example managers. These definitions are beyond the Sign Construction. They belong to the area of perception of an architect about the domain of interests of user. Using the language of Ferdinand de Saussure, this is a language which is used to speak. This is not a language people speak about. It cannot be separated from the consciousness of a speaker. The base forms are used to build the data network infrastructure.

Sign Construction consists of, first of all, a signified. This is a domain area which is understood as a domain of user interests. It represents economic, social, and business practices, and can be called the semantics of Sign Construction. Other component part of SC is a signifier. These are data represented in the way of data language. According to the idea of de Saussure, it consists of two parts. First part is langage (language) which describes relatively constant structure of domain area, its static. Second one is langue which reflects instance of domain area, its dynamics.

Data language is partitioned by three languages. This is a semantic language which set the correspondence between elements of data and semantics of Sign Construction. This is also a pragmatic language which describes the information opportunities and needs of user who uses data as an instrument of cognition of domain area or opportunities to impact it. The third part is a syntactic language of data processing for which just relations between elements of data and data carriers are important, but not relation with semantic or pragmatic. Every interrelated language consists of the structure (grammar) and content (vocabulary).

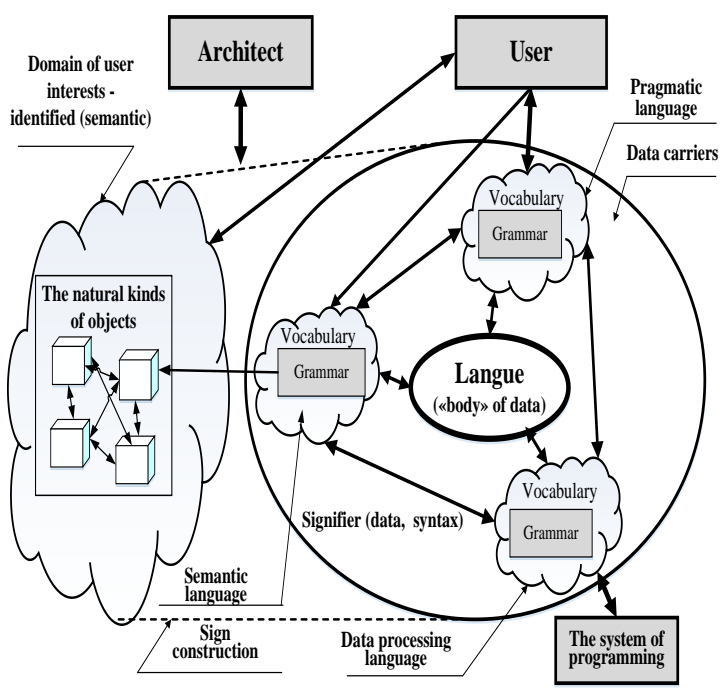

Figure 3. System-semiotic paradigm [3]

If we make comparison with simple table, head of a table is a langage, and a table body is a langue. Continuing the analogy, let us to notice that semantic, pragmatic, and syntactic aspects are interlaced in a table which complicating the final picture. Under that, tables could be used as building blocks for base forms and structures of data.

At the level of applied theory, the synthesis on the base of SSP generates applied paradigms of data, software, and organizations. According to them, software represents the unity of text of program (syntax, signifier) and dynamic object defined by the data processing. Processed data are the part of another Sign Construction. It signifies and connects the elements of the objective part of organization into common Sign Construction.

The application of gained theoretical apparatus allows receiving the base form of organizational sign which, in main features, repeats SSP (see Figure 4). 


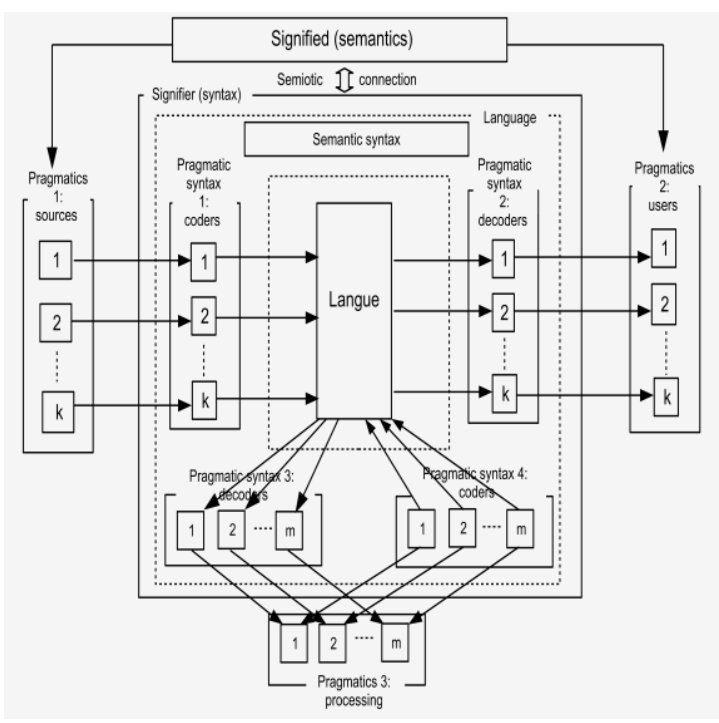

Figure 4. Paradigm of ontology of sign construction

[20]

Sources form initial data about status of semantics and code them into the language of signifier (on Figure - pragmatic syntax 1: coders). Coded data enriches langue. After that they are processed and transformed into processor's language (pragmatic syntax 3). Results of the processing come back to the signifier (pragmatic syntax 4). Then they are decoded for users (pragmatics 2). User (it could be automatic device) affects the signified with the help of obtained results.

Variety of realizations of this form unites into network data infrastructure. Results gained on the level of constructions and technologies form a base for solution of practical problems of infosphere development at the current stage. Therefore, the innovation activity started the movement along knowledge parabola from analysis of practice returns on the level of practice again but in the regime of synthesis and with an amount of knowledge received at each stage.

\section{Conclusions}

Information technologies revoked revolutionary changes in the sphere of information phenomena (infosphere) which included society, economy and business, in reality reduced to application of physical (not informational) technologies of data processing to information practices (not technologies). This contradiction together with variety of unsolved problems of infosphere development requires the strengthening of IT methodological and theoretical base.

To understand, where the infosphere development is now and where it is going, on the base of quasiphysical approach to non-physical phenomena the model of Paradigmatic Innovation Development (PIDev) was developed. According to it, IT originates in the sphere of physical phenomena, which is in the phase of scientifically substantiated innovations, and come to use in the sphere of information phenomena which is in the empirically-heuristic phase of development. At the current moment, it is collected enough of empirical material and ideas for the raise of infosphere to the next, paradigmatic, stage of development which precedes the phase of highly productive scientifically substantiated innovations.

Paradigmatic phase requires special regime of innovation activity. Methodology of work in this phase is presented by the parabola of knowledge which contains branches of analysis and synthesis, semiplanes of practice and forms of consciousness. The analysis reveals the existence of many serious practical problems which obstruct the development of infosphere, and the absence of informational, technological, and scientific (both fundamental and applied) support which is necessary for their solution.

At the same time necessary philosophical views can be found in the Vladimir Vernadskij's noosphere thinking, quasi-physical approach to non-physical phenomena of Merab Mamardashvili, and the philosophy of name of Aleksei Losev. At the branch of synthesis of the parabola of knowledge, these views are concretized in the model of PIDev and methods of Vertical Integration of Knowledge (VIK).

At the level of fundamental theory, the SystemSemiotic Paradigm (SSP) of Sign Construction is received. Formalized sign formations which belong to the sphere of economic organizations are called Sign Constructions. These are software, databases and bases of knowledge, and social, economic and business organizations by themselves. The paradigm represents the common core of Sign Constructions and can be applied to their whole variety.

At the level of applied theory, the synthesis on the base of SSP generates applied paradigms of data, software, and organizations. According to them, software represents the unity of text of program (syntax, signifier) and dynamic object defined by the data processing. Processed data are the part of another Sign Construction. It signifies and connects the elements of the objective part of organization into common Sign Construction.

The application of gained theoretical apparatus allows receiving the base form of organizational sign. Variety of realizations of this form unites into network data infrastructure. Results, gained at the level of constructions and technologies, were the necessary step on the way of practical development of infosphere.

\section{References}

[1] N.G. Carr. 2005. Блеск и нищета информационных технологий [Does it matter? Information Technology and the Corrosion of Competitive Advantage]. Moscow: Publishing House "Secret firmy". 
[2] М. K. Mamardashvili. 2011. Вильнюсские лекции по социальной философии (Опыт физической метафизики) [Vilnius lectures on social philosophy (The experience of physical metaphysics)]. Moscow: Izdatel'stvo «Azbuka».

[3] Polyakov, Maxim, Igor Khanin, and Nikolai Bormatenko. 2017. "Quasi-Physical Approach to Forming the Methodological and Theoretical Base of Infosphere Development". In International Conference on Information Society (I-Society-2017), Dublin July 17-19, 2017, pp. 44-47. Dublin: Infonomics Society.

[4] Ackoff, Russel Lincoln, and Frederick Edmund Emery. 1972. On purposeful systems. London: Tavistock Publications.

[5] Booch, Grady. 2004. Object-Oriented Analysis and Design with Applications (3rd Edition). Redwood City, CA, USA: Addison Wesley Longman Publishing Co., Inc.

[6] Khanin, Igor, Yuri Letser, and Nikolay Bormatenko. 2004. "Системно-семиотическое проектирование информационных технологий как развитие идей объектно-ориентированного подхода." [SystemSemiotic Project Design of Informational Technologies as a Development of the Ideas of ObjectOriented Approach]. In Mathematical and programing support of intellectual systems, Dnipropetrovsk, November 19. Dnipropetrovsk: DNU.

[7] Brödner, Peter. 2005. "Software is Orgware - A Semiotic Perspective on Computer Artifacts". Paper presented at Proceedings of the International Conference on User-driven IT Design and Quality Assurance (UITQ 05), Stockholm, 24-25May 2005. Stockholm: KTH. Accessed January 19, 2018.

http://wineme.wineme.fb5.uni-siegen.de/wpcontent/uploads/2016/11/uitqproceedings2005.pdf

[8] Scheer, August-Wilhelm. 1999. Бизнес-процессы. Основные понятия. Теория. Методы. [ARIS Business Process Frameworks]. Moscow: VestMetaTechnology.

[9] J.A.Zachman. 1987. "A framework for information systems architecture”, IBM Systems Journal Vol. 26 No 3, pp. 276-292. Accessed January 19, 2018.

http://www.zachman.com/images/ZI_PIcs/ibmsj2603 e.pdf

[10] Gruber, Tom. 2007. "Ontology". Tom Gruber. Accessed October 23, 2017. http://tomgruber.org/writing/ontology-definition2007.htm

[11] Shpet, Gustav. 1996. Явление и Смысл (Феноменология как Основная Наука и её Проблемы) [Phenomenon and Meaning (Phenomenology as Main Science and its Problems)]. Tomsk: Vodoley.

[12] Horizon 2020. The EU Framework Programme for Research and Innovation. Topic: Big Data technologies and extreme-scale analytics. Accessed January 19, 2018.

participants/portal/desktop/en/opportunities/h2020/top ics/ict-12-2018-2020.html

[13] Berners-Lee, Tim, James Hendler, and Ora Lassila. 2001. "Семантическая Сеть. Новая Форма Содержания Сети, Понятная Компьютерам,
Произведёт Революцию в ёё Возможностях.” [“Тhе Semantic Web. A New Form of Web Content That is Meaningful to Computers Will Unleash a Revolution of New Possibilities."]. School of Computer Science of The University of Manchester. Accessed October 23, 2017.

http://www.cs.man.ac.uk/ ezolin/logic/semantic_web rus.html.

[14] M. Polyakov, I. Khanin, and N. Bormatenko, "Quasiphysical Approach to Solving the Semiotics` Practical Productivity Paradox", 4th Annual International Conference on Philosophy: Yesterday, Today \& Tomorrow (PYTT 2016) and 4th Annual International Conference on Contemporary Cultural Studies (CCS 2016), Singapoore, 2016. Accessed January 19, 2018. http://dl4.globalstf.org/?wpsc-product=quasiphysical-approach-to-solving-the-semiotics-practicalproductivity-paradox

[15] R. K. Stamper, "Organisational semiotics: Informatics without the computer?" in Information, organisation and technology: Studies in organisational semiotics, K.Liu, R. J. Clarke, P. Bøgh Andersen, and R. K. Stamper, Eds. Boston, MA: Kluwer Academic Publishers, 2001, pp. 115-171.

[16] D. Fensel, J.A. Hendler, H. Lieberman, and W. Wahlster, Spinning the Semantic Web: Bringing the World Wide Web to Its Full Potential. Cambridge: The MIT Press, 2005.

[17] N. V. Bormatenko, A systemic-semiotic approach to the development of the concept of software. Moscow: CNITEI, 1982.

[18] V.Vernadskij, The biosphere and the noosphere. Moscow: Airis-press, 2004.

[19] A. F.Losev, The philosophy of name. From the early works. Moscow: «Pravda», 1990.

[20] Polyakov Maxim, Igor Khanin, Nikolay Bormatenko, and Sergiy Kosenchuk. 2018. "Ontology of Sign: A Key to Information and Technological Advancement of the Knowledge Society." The International Journal of Technology, Knowledge, and Society 14(3): 27-45. 